\title{
Subthreshold yellow laser for fovea- involving diabetic macular edema in a series of patients with good vision: effectiveness and safety of a fovea-sparing technique
}

\author{
Alejandro Filloy ${ }^{1 *}$ (D) Victor Chong $^{2}$ and Eduard Solé
}

\begin{abstract}
Purpose: Patients with center-involved diabetic macular edema (CI-DME) with good visual acuity (VA) represent a controversial clinical scenario in which a subthreshold laser might be a reasonable approach. We report a case series of patients with CI-DME with VA better than 20/32 who were treated with a subthreshold $577 \mathrm{~nm}$ (yellow) laser.

Methods: The area of retinal thickening on OCT was treated with confluent laser spots at individually titrated power. The fovea was spared from treatment. Effectiveness and safety were evaluated through OCT and autofluorescence (AF) as well as BCVA.

Results: A total of 23 eyes from 19 patients were treated. VA ranged from 20/20 to 20/30. The follow-up period ranged from 6 to 18 months. Edema in OCT resolved completely at the end of follow-up in 56.5\% (13/23) of the cases. Central retinal thickness was reduced at 12 weeks and at the end of follow-up, with a mean reduction of $16.9 \mu \mathrm{m}$ and $22 \mu \mathrm{m}$, respectively (paired t-test $p=0.001$ and 0.0003). VA remained stable. The laser was invisible (OCT, AF, Fundoscopy) in $91,3 \%$ (21/23) of eyes.

Conclusions: A fovea-sparing yellow subthreshold laser was safe and effective for treating CI-DME patients with good VA in this case series. This technique is of interest to prevent the progression of mild edema and might avoid or reduce the use of more invasive and expensive therapies. Excluding the fovea from the treated area does not seem to affect the results, which is of interest to novel laser practitioners.
\end{abstract}

Keywords: Autofluorescence, Diabetic, Fovea, Subthreshold, Yellow

\footnotetext{
* Correspondence: alejandrofilloy@gmail.com

'Ophthalmology department, Joan XXIII University Hospital, Rovira i Virgili

University, Mallafré i Guasch, 4, 43002 Tarragona, Spain

Full list of author information is available at the end of the article
}

(c) The Author(s). 2020 Open Access This article is licensed under a Creative Commons Attribution 4.0 International License, which permits use, sharing, adaptation, distribution and reproduction in any medium or format, as long as you give appropriate credit to the original author(s) and the source, provide a link to the Creative Commons licence, and indicate if changes were made. The images or other third party material in this article are included in the article's Creative Commons licence, unless indicated otherwise in a credit line to the material. If material is not included in the article's Creative Commons licence and your intended use is not permitted by statutory regulation or exceeds the permitted use, you will need to obtain permission directly from the copyright holder. To view a copy of this licence, visit http://creativecommons.org/licenses/by/4.0/. The Creative Commons Public Domain Dedication waiver (http://creativecommons.org/publicdomain/zero/1.0/) applies to the data made available in this article, unless otherwise stated in a credit line to the data. 


\section{Background}

Diabetic macular edema (DME) is a complex disease that presents itself in a wide variety of clinical scenarios that drive the need for individualized treatment [1]. One controversial setting involves patients who retain good visual acuity (VA) but display early center-involved DME (CI-DME) on OCT. Recently, DRCR.net has assessed whether anti-VEGF therapies would be useful in this situation versus observation and laser photocoagulation [2]. However, anti-VEGF is still invasive and expensive, so at least to the present day, close observation has become the standard of care, as the retinal damage caused by conventional lasers is becoming increasingly unacceptable to patients and retinal specialists $[3,4]$. The use of a subthreshold laser (STL), which does not cause cicatricial or tissue-changing effects, is considered a safe technique to work around and even on the fovea [5-9] since no clinically visible effects appear on the fundus, optical coherence tomography (OCT) or autofluorescence (AF), the latter being especially sensitive to any disturbances/damages in the retinal pigment epithelium (RPE) [10]. The latest developments in STL, such as the partly or fully automated delivery systems that guarantee that the edematous area is treated densely enough, help increase its efficacy, thus making this technique more attractive $[11,12]$. We present a study on the effectiveness of a subthreshold $577 \mathrm{~nm}$ (yellow) subliminal laser on VA and OCT and safety on AF for the treatment of CI-DME patients with good VA (20/32 or better). In this study, we administered the laser through a "fovea-sparing" technique, which avoids delivering laser treatment on the fovea itself and up to $100 \mu \mathrm{m}$ from the fovea.

\section{Methods}

This was a retrospective consecutive case series. The inclusion criterion was OCT-confirmed CI-DME. To qualify for CI-DME, OCT had to display intraretinal cysts (IRC) with or without intraretinal exudates (IRE) or neurosensory detachment (NSD) in the central $1 \mathrm{~mm}$ subfield. The patients were asymptomatic (without any VA deterioration, metamorphopsia or other newly acquired visual symptoms) with a best corrected visual acuity (BCVA) better than 20/32. Patients who had received treatment for $\mathrm{DME}$ in the three months prior to baseline were excluded.

Swept-Source OCT (Triton, Topcon, Japan) was employed. AF was taken using the same device and fundus photography was also taken at baseline and at every follow-up visit. Treatment was delivered through a yellow wavelength $(577 \mathrm{~nm})$ subthreshold laser (Subliminal Easyret, Quantel Medical, Cournon d'Auvergne, France). Treatments were performed by a single surgeon (A. F). The standard parameters were $5 \%$ duty cycle, spot size $160 \mu \mathrm{m}$ in diameter and $0.2 \mathrm{~s}$ in duration. The power to employ was titrated case by case at $1 / 3$ of the minimum power needed to produce a barely visible whitening of the healthy retina in the macular periphery. Laser spots were delivered in a confluent manner to cover the entire edematous area on the OCT thickness map as well as $200 \mu \mathrm{m}$ of flat retina around this area. The fovea itself and $100 \mu \mathrm{m}$ of the surrounding area were spared from treatment. Before discharge, the patients were instructed to consult us if they noticed any symptoms. They were scheduled for evaluation with VA, OCT and AF at 12 weeks after STL and every 12 weeks thereafter.

The collected data were analyzed with IBM SPSS statistics 25.0 (IBM, USA). Statistical significance was considered with $p$ values of at least 0.05 .

\section{Results}

A total of 23 eyes (19 patients) met the inclusion criteria (Table 1). The mean age was 61,3 years, and 15 patients had type-II diabetes mellitus (DM) while 4 had type I DM. Six of the patients were treatment naive, while thirteen received previous treatment for DME (7 received anti-VEGF, 5 focal laser, 1 both). The initial VA ranged from $20 / 20$ to $20 / 32$, averaging 20/25. The follow-up period ranged from 6 to 18 months (average 12.5 months). The mean power used was $396 \mathrm{~mW}$, and the mean number of spots delivered was 288. VA after treatment remained stable $(p=0.16$, paired $\mathrm{t}$ test), with no patients showing VA loss. Edema in OCT resolved completely in $30.4 \%(7 / 23)$ of the cases, while another $52.2 \%(12 / 23)$ showed improvement at the first postlaser visit. The total number of resolved cases increased to $56.5 \%(13 / 23)$ at the end of the follow-up. The OCTmeasured central retinal thickness (CRT) decreased from 301 to $284 \mu \mathrm{m}$ on average, a total of $17 \mu \mathrm{m}$, after the first 12 weeks $(p=0.001$, paired t test). At the end of the follow-up, the average CRT decrease was $22 \mu \mathrm{m}$ ( $p=$ 0.0003, paired t test) (Figs. 1 and 2). One case showed a further increase in CRT $(+38 \mu \mathrm{m})$ without VA loss. None of the patients reported earlier than the scheduled visit for VA loss or the presence of any significant symptoms. Laser treatment was invisible on Fundoscopy, OCT and FA in $91.3 \%(21 / 23)$ of the cases. The 2 cases where the highest power was used displayed some visible spots as hyperautofluorescent discrete dots on AF as well as mild RPE disturbance on OCT; these 2 patients did not report any symptoms even on direct questioning. No other secondary effects were noted.

\section{Discussion}

The use of a subthreshold laser for the treatment of DME patients is known to lead to better results in terms of effectiveness and safety than conventional laser 
Table 1 Results

\begin{tabular}{|c|c|c|c|c|c|c|c|c|c|c|c|c|c|}
\hline Patient & Eye & DM & OCT & $\begin{array}{l}\text { PreL } \\
\text { CRT }\end{array}$ & $\begin{array}{l}\text { PostL CRT (12 } \\
\text { week) }\end{array}$ & $\begin{array}{l}\text { Last PostL } \\
\text { CRT }\end{array}$ & $\begin{array}{l}\text { Decrease in } \\
\text { CRT }\end{array}$ & $\begin{array}{l}\text { Power } \\
(\mathrm{mW})\end{array}$ & Spots & $\begin{array}{l}\text { Follow up } \\
\text { (months) }\end{array}$ & $\begin{array}{l}\text { Changes on } \\
\text { AF }\end{array}$ & $\begin{array}{l}\text { PreL } \\
\text { VA }\end{array}$ & $\begin{array}{l}\text { PostL } \\
\text { VA }\end{array}$ \\
\hline 1 & RE & $\|$ & IRC & 288 & 257 & 250 & 38 & 450 & 350 & 18 & NO & $20 / 22$ & $20 / 22$ \\
\hline 1 & LE & $\|$ & IRC & 280 & 265 & 263 & 17 & 450 & 460 & 10 & NO & $20 / 22$ & $20 / 22$ \\
\hline 2 & LE & I & IRC & 296 & 284 & 277 & 19 & 325 & 80 & 15 & NO & $20 / 22$ & $20 / 20$ \\
\hline 3 & RE & 1 & $\begin{array}{l}\text { IRC, } \\
\text { NSD }\end{array}$ & 302 & 283 & 276 & 26 & 350 & 150 & 9 & NO & $20 / 20$ & $20 / 20$ \\
\hline 4 & RE & $\|$ & IRC & 303 & 268 & 247 & 56 & 350 & 200 & 10 & NO & $20 / 22$ & $20 / 22$ \\
\hline 5 & RE & 1 & $\begin{array}{l}\text { IRC, } \\
\text { IRE }\end{array}$ & 301 & 288 & 295 & 6 & 400 & 60 & 12 & NO & $20 / 25$ & $20 / 22$ \\
\hline 5 & LE & 1 & IRC & 287 & 272 & 251 & 36 & 300 & 180 & 9 & NO & 20/32 & $20 / 32$ \\
\hline 6 & RE & $\|$ & IRC & 269 & 274 & 254 & 15 & 350 & 200 & 14 & NO & $20 / 28$ & $20 / 28$ \\
\hline 7 & LE & $\|$ & $\begin{array}{l}\text { IRC, } \\
\text { IRE }\end{array}$ & 275 & 267 & 270 & 5 & 500 & 180 & 15 & YES & $20 / 28$ & $20 / 25$ \\
\hline 8 & RE & $\|$ & IRC & 258 & 226 & 240 & 18 & 400 & 200 & 15 & NO & $20 / 28$ & $20 / 25$ \\
\hline 8 & LE & $\|$ & $\begin{array}{l}\text { IRC, } \\
\text { IRE }\end{array}$ & 243 & 230 & 230 & 13 & 500 & 180 & 17 & YES & $20 / 32$ & $20 / 25$ \\
\hline 9 & LE & $\|$ & $\begin{array}{l}\text { IRC, } \\
\text { IRE }\end{array}$ & 270 & 260 & 260 & 10 & 450 & 250 & 13 & NO & $20 / 32$ & $20 / 25$ \\
\hline 10 & RE & 1 & IRC & 376 & 350 & 323 & 53 & 300 & 480 & 9 & NO & $20 / 20$ & $20 / 20$ \\
\hline 10 & LE & 1 & $\begin{array}{l}\text { IRC, } \\
\text { NSD }\end{array}$ & 510 & 431 & 442 & 68 & 300 & 560 & 9 & NO & $20 / 20$ & $20 / 20$ \\
\hline 11 & RE & $\|$ & $\begin{array}{l}\text { IRC, } \\
\text { IRE }\end{array}$ & 355 & 393 & 393 & -38 & 400 & 380 & 6 & NO & $20 / 32$ & $20 / 25$ \\
\hline 12 & RE & $\|$ & IRC & 335 & 333 & 332 & 3 & 382 & 350 & 9 & NO & $20 / 28$ & $20 / 28$ \\
\hline 13 & LE & $\|$ & $\begin{array}{l}\text { IRC, } \\
\text { IRE }\end{array}$ & 254 & 226 & 226 & 28 & 325 & 300 & 7 & NO & $20 / 22$ & $20 / 22$ \\
\hline 14 & RE & $\|$ & $\begin{array}{l}\text { IRC, } \\
\text { IRE }\end{array}$ & 324 & 320 & 322 & 2 & 300 & 400 & 7 & NO & $20 / 22$ & $20 / 22$ \\
\hline 15 & LE & $\|$ & IRC & 341 & 295 & 293 & 48 & 425 & 160 & 12 & NO & $20 / 32$ & $20 / 25$ \\
\hline 16 & LE & $\|$ & NSD & 288 & 256 & 234 & 54 & 450 & 450 & 12 & NO & $20 / 25$ & $20 / 20$ \\
\hline 17 & LE & $\|$ & $\begin{array}{l}\text { IRC, } \\
\text { IRE }\end{array}$ & 282 & 266 & 252 & 30 & 350 & 400 & 9 & NO & $20 / 20$ & $20 / 20$ \\
\hline 18 & RE & $\|$ & $\begin{array}{l}\text { IRC, } \\
\text { IRE }\end{array}$ & 259 & 250 & 242 & 17 & 350 & 300 & 9 & NO & $20 / 20$ & $20 / 20$ \\
\hline 19 & LE & $\|$ & IRE & 226 & 226 & 226 & 0 & 700 & 350 & 9 & NO & $20 / 28$ & $20 / 28$ \\
\hline
\end{tabular}

DM Diabetis Mellitus, PreL Pre Laser, PostL Post Laser, CRT Central retinal thickness, AF Autofluorescence, VA Visual acuity, IRC Intraretinal cysts, NSD Neurosensory detachment, IRE Intraretinal exudates

photocoagulation [13]. It might also decrease the injection burden in these patients [14]. In our study, a yellow subthreshold laser applied with a fovea-sparing technique with $1 / 3$ power titration was shown to be a safe and effective treatment for CI-DME in patients presenting with good VA. In addition to preserving their VA, 95.7\% (22/23) of the treated eyes improved to either complete or partial anatomical normalization at the last follow-up, which is likely to prevent VA loss in the near future.

CI-DME with good VA is a controversial clinical setting because of the disadvantages of the most commonly applied treatment strategies [3]: observation, which may lead to further deterioration with VA loss, and intravitreal therapy, which has a high cost and potential complications such as endophthalmitis that, although rare [15], is especially devastating when treating asymptomatic patients.

Recently, the DRCR network assessed this controversy [2] in a two-year randomized study comparing three arms: aflibercept, laser photocoagulation and observation, the last two receiving aflibercept as needed in the case of visual deterioration. The study concluded that observation is a reasonable option considering that there was a lack of significant differences in visual acuity between the three arms at the end of the study. It must be 


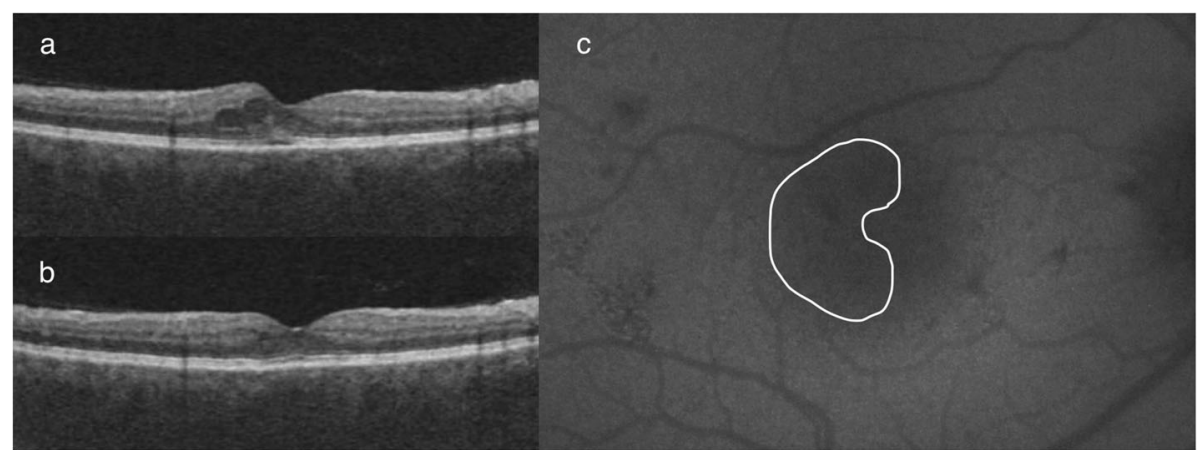

Fig. 1 This asymptomatic patient was diagnosed with DME during routine examination. Intraretinal cysts and early neurosensory detachment are visible. The CRT at this point was $302 \mu \mathrm{m}$. a. Twelve weeks after STL treatment, there was a marked improvement, with a decrease in CRT to $283 \mu \mathrm{m}$ (b), as well as a lack of visible laser reaction on AF (c). Vision remained 20/20 at all times. The demarcated area on AF shows the treatment zone (also in Fig. 2). The OCT protocol for these images was a macular cube $9 \times 9 \mathrm{~mm}$

noted, however, that up to $34 \%$ of the patients in the observation group and $25 \%$ in the laser photocoagulation group required treatment with aflibercept at some point during the study (a median of 7 injections per patient over 2 years). None of our patients needed intravitreal therapy due to a deterioration in VA so far. In addition, the laser technology employed in that study was traditional ETDRS laser photocoagulation instead of subthreshold technology. It must also be noted, however, how the number of patients requiring aflibercept was lower in the laser arm than in the observation arm.

The safety of a transfoveal $810 \mathrm{~nm}$ (infrared) subthreshold laser has been previously evaluated in a similar clinical setting [9]. The results we obtained with the fovea-sparing technique and $577 \mathrm{~nm}$ wavelength were effective, and AF further supported the safety of this approach. Previous studies failed to demonstrate differences in outcomes between infrared and yellow wavelengths for the treatment of mild DME [16]. Treating the fovea directly remains controversial and is considered a risk for these asymptomatic patients with good vision. Success on the subthreshold relies on treating a large surface area, thus stimulating enough RPE cells to produce a clinically significant response [17, 18]. Since the fovea and its surroundings represent a small surface, excluding it from treatment means 3 or 4 fewer $160 \mu \mathrm{m}$ spots at most, which will hardly be relevant when the average numbers of these treatments are usually around the hundreds. The therapeutic effect of treating the neighboring area will likely extend to the fovea. We believe that the fovea-sparing technique is of particular interest, as STL is gaining interest among retinal specialists. This makes the transition from conventional laser to STL easier, as novel STL surgeons can become

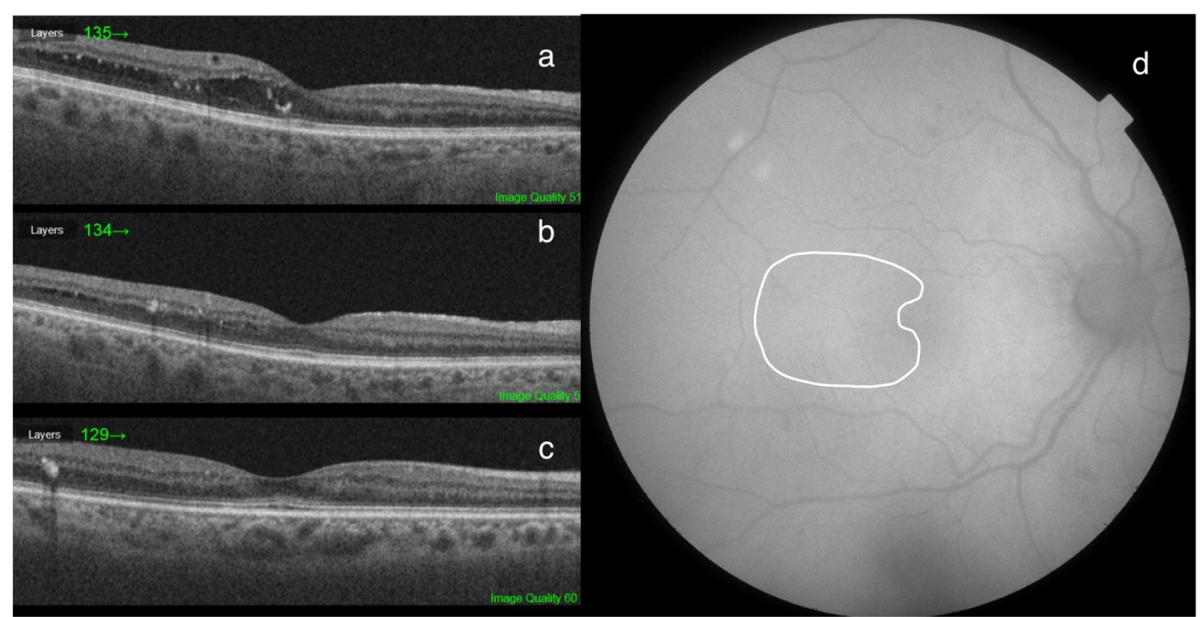

Fig. 2 This patient showed remarkable improvement at the first post-laser visit (b, 12 weeks). At the next follow-up visit, we observed a slight additional improvement (c, 24 weeks). AF (d) does not show RPE disturbance. VA remained 20/25. CRT decreased from $282 \mu \mathrm{m}$ at baseline to $266 \mu \mathrm{m}$ at the first follow-up visit and finally $252 \mu \mathrm{m}$ 
familiar with the new parameters and delivery systems without the fear of the potentially devastating effect of a foveal or near-foveal laser burn.

We prefer individual titration to the use of standardized power to all patients to try to provide a treatment intense enough while remaining at the subthreshold. The reason we used $160 \mu \mathrm{m}$ spots was to reach a compromise between the more widely used $200 \mu \mathrm{m}$ (avoids relatively large unstimulated areas for missed spots) and $100 \mu \mathrm{m}$ (takes much longer to treat the same area with smaller spots) spots. We employed the 5\% duty cycle, which is currently the standard [6].

The two cases with visible spots on AF were probably related to an overestimation of power during titration. The patient with an increase in retinal thickness despite treatment presented 3 large microaneurysms within the thickened retina. The exudation coming from these relatively large lesions might require more than one session of STL.

\section{Conclusions}

STL has been shown to be a safe and effective treatment alternative in this case series of CI-DME patients. The traditional observation and intravitreal treatment options present their own limitations. Excluding the fovea from treatment does not seem to impair the results compared to those in previous studies in similar patients. The main limitations of the present study are its retrospective nature, the relatively small number of patients included and the relatively short follow-up. A randomized prospective study to compare observation, STL and intravitreal anti-VEGF should be considered to firmly establish the usefulness of this technique to provide a more affordable and safer treatment for these asymptomatic patients.

\section{Abbreviations}

AF: Autofluorescence; BCVA: Best Corrected Visual Acuity; CI-DME: CenterInvolving Diabetic Macular Edema; CRT: Central Retinal Thickness; DME: Diabetic Macular Edema; IRC: Intraretinal Cysts; IRE: Intraretinal Exudates; NDS: Neusosensory Detachment; OCT: Optical Coherence Tomography; RPE: Retinal Pigment Epithelium; STL: Subthreshold Laser; VA: Visual Acuity; VEGF: Vascular Endothelial Growth Factor

\section{Acknowledgements}

Not applicable.

\section{-Competing interests}

AF has received lecture fees by Allergan, Bryll Pharma and Quantel Medical. $\mathrm{VC}$ is an employee of Boehringer Ingelheim International $\mathrm{GmBH}$ but Boehringer is not involved or endorsed this study in any way. VC is also a consultant of Quantel Medical.

\section{-Author contributions}

All authors have read and approved the manuscript. A.F Has worked on the design, execution, data collection and analysis and manuscript elaboration. V.C has worked on data analysis and manuscript elaboration. E.S Has worked on the design and data collection.

\section{-Funding}

This research did not receive any funding.

\section{-Availability of data and materials}

The datasets used and/or analysed during the current study are available from the corresponding author on reasonable request.

\section{-Consent for publication}

Written informed consent to publish potentially identifiable data was obtained from the patients, none of the patients are under 18.

\section{-Ethics approval and consent to participate}

Subjects have given their written informed consent and the study protocol was approved by the institute's committee on human research. (Comité

Ètica Clínica i Assistencial Hospital Universitari Joan XXIII).

\section{Author details}

'Ophthalmology department, Joan XXIII University Hospital, Rovira i Virgili University, Mallafré i Guasch, 4, 43002 Tarragona, Spain. ${ }^{2}$ Arnott Eye Associates, London and University of Oxford, Oxford, UK.

Received: 16 April 2020 Accepted: 30 June 2020

Published online: 06 July 2020

\section{References}

1. Bandello F, Battaglia Parodi M, Lanzeta P, Lowenstein A, Massin P, Menchini F, et al. Diabetic Macular Edema. Dev Ophthalmol. 2017;58:102-38.

2. Baker CW, Glassman AR, Beaulieu WT, Antoszyk AN, Browning DJ, Chalam KV, et al. DRCR Retina Network. Effect of Initial Management With Aflibercept vs Laser Photocoagulation vs Observation on VisionLoss Among Patients With Diabetic Macular Edema Involving the Center of the Macula and GoodVisual Acuity: A Randomized Clinical Trial. JAMA. 2019;321(19): 1880-94.

3. Busch C, Fraser-Bell S, Zur D, Rodriguez-Valdés PJ, Cebeci Z, Lupidi M, et al. International retina group. Real-world outcomes of observation and treatment in diabetic macular edema with very good visual acuity: the OBTAIN study. Acta Diabetol. 2019;56(7):777-84.

4. Relhan N, Flynn HW Jr. The early treatment diabetic retinopathy study historical review andrelevance to today's management of diabetic macular edema. Curr Opin Ophthalmol. 2017;28(3):205-12.

5. Sholz P, Altay L, Fauser S. A (2017) Review of subthreshold micropulse laser for treatment of macular disorders. Adv Ther; 34(7): 1528-1555.

6. Chehade L, Chidlow G, Wood J, Casson RJ. Short-pulse duration retinal lasers: a review. Clin Exp Ophthalmol. 2016;44(8):714-21.

7. Luttrull JK, Spink CJ. Serial optical coherence tomography of subthreshold diode laser micropulse photocoagulation for diabetic macular edema. Ophthalmic Surg Lasers Imaging. 2006;37(5):370-7.

8. Vujosevic S, Martini F, Longhin E, Convento E, Cavarzeran F, Midena E. Subthreshold micropulse infrared laser in center-involving diabetic macular edema: morphologic and functional safety. Retina. 2015;35(8):1594-603.

9. Luttrull JK, Sinclair SH. Safety of transfoveal subthreshold diode micropulse laser for fovea-involving diabetic macular edema in eyes with good visual acuity. Retina. 2014;34(10):2010-20.

10. Frampton GK, Kalita N, Payne L, Colquitt JL, Loveman E, Downes SL, et al. Fundus autofluorescence imaging: systematic review of test accuracy for the diagnosis and monitoring of retinal conditions. Eye (Lond). 2017;31(7): 995-1007.

11. Lutrull JK. Low-intensity/high-density subthreshold díode micropulse laser for central serous chorioretinopathy. Retina. 2016;36(9):1658-63.

12. Malik KM, Mansouri A, Steiner JN, Glaser BM. Low-intensity/high-density subthreshold microPulse diode laser for chronic central serous chorioretinopathy. Retina. 2015;35(3):532-6.

13. Figueira J, Khan J, Nunes S, Sivaprasad S, Rosa A, de Abreu JF, et al. Prospective controlled trial comparing sub-threshold micropulse diode laserphotocoagulation and conventional green laser for clinically significant diabetic macular oedema. Br J Ophthalmol. 2009;93(10):1341-4.

14. Moisseiev E, Abbassi S, Thinda S, Yoon J, Yiu G, Morse LS. Subthreshold micropulse laser reduces anti-VEGF injection burden in patients with diabetic macular edema. Eur J Ophthalmol. 2018;28(1):68-73.

15. Gupta A, Sun JK, Silva PS. Complications of Intravitreous injections in patients with diabetes. Semin Ophthalmol. 2018;33(1):42-50. 
16. Vujosevic S, Martini F, Longhin E, Convento E, Cavarzeran F, Midena E. Subthreshold micropulse yellow laser versus subthreshold micropulse infrared laser in center-involving diabetic macular edema: morphologic and functional safety. Retina. 2015;35(8):1594-603.

17. Inagaki K, Shuo T, Katakura K, Ebihara N, Murakami K, Ohkoshi K. (2015) Sublethal Photothermal stimulation with a micropulse laser induces heat shock protein expression in ARPE-19 cells. J Ophthalmol. 2015;2015:729792 Epub Nov 30

18. Midena E, Bini S, Marina F, Enrica C, Pilotto E, Micera A, et al. Changes of aqueus humor Müller cells' biomarkers in human patients affected by diabetic macular edema after subthreshold micropulse laser treatment. Retina. 2018;40(1):126-34.

\section{Publisher's Note}

Springer Nature remains neutral with regard to jurisdictional claims in published maps and institutional affiliations.

Ready to submit your research? Choose BMC and benefit from:

- fast, convenient online submission

- thorough peer review by experienced researchers in your field

- rapid publication on acceptance

- support for research data, including large and complex data types

- gold Open Access which fosters wider collaboration and increased citations

- maximum visibility for your research: over $100 \mathrm{M}$ website views per year

At BMC, research is always in progress.

Learn more biomedcentral.com/submissions 